\title{
Doxycycline is an NF-kB inhibitor that induces apoptotic cell death in malignant T-cells
}

\author{
Carolina V. Alexander-Savino1, Matthew S. Hayden'1, Christopher Richardson ${ }^{2}$, \\ Jiyong Zhao ${ }^{3}$, Brian Poligone ${ }^{1,4}$ \\ ${ }^{1}$ Rochester General Hospital Research Institute, Center for Cancer and Blood Disorders, Rochester, NY, USA \\ ${ }^{2}$ Division of Allergy, Immunology and Rheumatology, University of Rochester School of Medicine, Rochester, NY, USA \\ ${ }^{3}$ Department of Biomedical Genetics, University of Rochester School of Medicine, Rochester, NY, USA \\ ${ }^{4}$ Rochester Skin Lymphoma Center, Fairport, NY, USA \\ Correspondence to: Brian Poligone, email: bpoligone@roclymphoma.com \\ Keywords: non-Hodgkin's lymphoma, signal transduction, apoptosis, drug repurposing, doxycycline \\ Received: February 26, $2016 \quad$ Accepted: September 24, $2016 \quad$ Published: October 06, 2016
}

\section{ABSTRACT}

Cutaneous T-cell Lymphoma (CTCL) is a rare non-Hodgkin's lymphoma that can affect the skin, blood, and lymph nodes, and can metastasize at late stages. Novel therapies that target all affected disease compartments and provide longer lasting responses while being safe are needed. One potential therapeutic target is NF-кB, a regulator of immune responses and an important participant in carcinogenesis and cancer progression. As a transcription factor, NF- $\mathrm{kB}$ targets genes that promote cell proliferation and survival. Constitutive or aberrant activation of NF-кB is encountered in many types of cancer, including CTCL.

Recently, while analyzing gene-expression profiles of a variety of small molecule compounds that target NF-кB, we discovered the tetracycline family of antibiotics, including doxycycline, to be potent inhibitors of the NF-кB pathway. Doxycycline is well-tolerated, safe, and inexpensive; and is commonly used as an antibiotic and anti-inflammatory for the treatment a multitude of medical conditions.

In our current study, we show that doxycycline induces apoptosis in a dose dependent manner in multiple different cell lines from patients with the two most common subtypes of CTCL, Mycosis Fungoides (MF) and Sézary Syndrome (SS). Similar results were found using primary CD4+ $T$ cells from a patient with SS. Doxycycline inhibits TNF induced NF- $\kappa$ B activation and reduces expression of NF- $\kappa B$ dependent antiapoptotic proteins, such as BCL2 $\alpha$. Furthermore, we have identified that doxycycline induces apoptosis through reactive oxygen species.

\section{INTRODUCTION}

Cutaneous T-cell Lymphomas (CTCL) are rare forms of non-Hodgkin's lymphomas that encompass about half of all mature T-cell malignancies and primarily involve the skin [1]. Mycosis fungoides (MF) and Sézary Syndrome (SS) encompass about half of all CTCLs. MF is characterized by the presence of patches, plaques, or tumors, and in more advanced stages, it can present with erythroderma, affect the blood and lymph nodes, and metastasize to other organs [2]. Both MF and SS may be associated with severe pruritus that often reduces quality of life [2]. Although the median survival can vary from 10-35 years in those with early stage disease, this drastically reduces to only 1.5 years for those with advanced staged disease [3]. Additionally, one in four people with early stage disease progress to more advanced stages with a drastic reduction in overall survival rate to 4 years $[4,5]$.

The heterogeneity in the histological and clinical presentations of CTCL presents a challenge to clinicians despite recent advances in treatment options for this 
disease $[2,6,7]$. There is an unmet need for therapies that can be effective in all disease compartments while being safe $[2,7]$. There are currently few systemic therapies available, and these have overall response rates of $20-45 \%$ and complete response rates of less than $20 \%$. The highest median duration of response is 15 months [8-11]. Many of these patients do not respond to standard chemotherapy [12]. Moreover, the toxicities of these therapies are often significant. Therefore, new therapies that are effective, safe, and tolerable are needed [13].

The "Connectivity Map" is a research effort of the Broad Institute that links gene expression patterns produced after treatment with over 1,300 small-molecule compounds [14]. This map facilitates the discovery of new drugs for the treatment of diseases by allowing researchers to screen for compounds that could target genes known to be involved in pathways of disease, such as those controlled by transcription factor NF- $\kappa \mathrm{B}$. $\mathrm{NF}-\kappa \mathrm{B}$ regulates genes that promote cell proliferation, metastasis, angiogenesis, invasion, inflammation, and cell survival. NF- $\kappa B$ is a key regulator of immune response and important in carcinogenesis and cancer progression [15]. Constitutive expression of NF- $\kappa \mathrm{B}$ is associated with a multitude of cancers, including CTCL [16-19]. We previously reported our effort to identify novel targets of the NF- $\kappa$ B pathway using the Connectivity map and doxycycline was identified as a novel inhibitor of this pathway [20].

Doxycycline is an inexpensive and widely used tetracycline, commonly known for its antibiotic properties, that was first synthesized from chlortetracycline in 1967 [21]. Chlortetracycline is the parent structure for all tetracyclines and is naturally found in Streptomyces aureofaciens [22]. Doxycycline's antibiotic effects come from its ability to bind to the bacterial ribosome's 30s subunit and inhibit protein synthesis. This makes it capable of treating both gram positive and gram negative bacterial infections.

Independent from its antimicrobial activities, doxycycline has a vast range of pharmacological properties, including its ability to suppress inflammation due to inhibition of metalloproteinases, hydrolases, and cytokine production $[23,24]$. Thus, it has been utilized for the treatment of various conditions, including cardiovascular and neurological disorders, periodontal disease, malaria, rickettsial and chlamydial infections, Lyme disease, and inflammatory dermatologic disorders such as rosacea, acne vulgaris, and bullous pemphigoid [25-27]. Doxycycline is usually well tolerated and has a low side-effect profile [28]. These therapeutic benefits, along with its inhibitory effect on NF- $\kappa \mathrm{B}$ target genes, and its commercial availability, significantly reduces the amount of time it would take to bring a drug to the market, which prompted us to study the effects of doxycycline in cells from patients with CTCL.

\section{RESULTS}

\section{Doxycycline treatment of CTCL cell lines leads to cell death}

Doxycycline was added at varying concentrations to actively growing cell lines H9, Hut78, HH, MyLa, and MJ. Viability was assessed using trypan blue after 4 days of treatment (Figure 1A-1E). Most of the cell lines, including $\mathrm{H} 9, \mathrm{HH}$, Hut78, and MyLa, were killed by doxycycline in a dose dependent manner. However, MJ showed more resistance to doxycycline killing. Although there was some cell cycle arrest observed in the MJ cells at higher concentrations of doxycycline, even after 7 days of treatment, at the highest dose of doxycycline, MJ cells were still viable compared to the sensitive cell lines that showed essentially 100\% killing after 4 days (data not shown).

These results were interesting as they correlated with results that were discovered while examining NF$\kappa \mathrm{B}$ activity in these CTCL cell lines. I $\mathrm{B} \alpha$ keeps NF- $\kappa \mathrm{B}$ sequestered in the cytoplasm, thereby preventing it from performing its function as a transcription factor in the nucleus. TNF $\alpha$ (TNF) induces phosphorylation of IкB $\alpha$, triggering its ubiquitination and subsequent degradation in the proteasome. This frees NF- $\kappa \mathrm{B}$ in the cytoplasm to migrate into the nucleus and transcribe genes that are crucial for cell survival and proliferation [29-31]. Interestingly, the sensitivity to doxycycline killing (Figure 1A-1E) correlated with the cell line's ability to induce NF- $\kappa \mathrm{B}$ (Figure 2A-2B). TNF treatment increased $\mathrm{NF}-\kappa \mathrm{B}$ pathway activation in Hut78, H9, MyLa, and $\mathrm{HH}$ cell lines (Figure 2A). In contrast, despite changes in baseline NF- $\mathrm{NB}$ pathway activation, we did not observe increased phosphorylation of $\mathrm{I} \kappa \mathrm{B} \alpha$ in either $\mathrm{MJ}$ or Hut102 cells after TNF stimulation (Figure 2B). This suggests that CTCLs may have multiple mechanisms through which NF- $\kappa \mathrm{B}$ is activated, as is known to occur in Activated B-cell like (ABC) and Germinal Center B-like (GBC) Diffuse Large B-Cell Lymphomas [16, 32]. Interestingly, of the CTCL cell lines studied, both MJ and Hut102 are known to be HTLV positive while the others (Hut78, H9, MyLa, and HH), and, in fact most primary CTCLs, are known to be HTLV negative. This is of particular interest given that HTLV Tax has pleiotropic effects on the NF- $\kappa \mathrm{B}$ pathway and is well known to activate both canonical and non-canonical NF$\kappa \mathrm{B}$ pathways [33].

\section{Doxycycline inhibits NF-кB in CTCL cell lines}

We have previously shown that doxycycline is an inhibitor of NF- $\mathrm{NB}$ in some cell lines [20]. Given that doxycycline induces cellular killing in CTCL cell lines that also can be further activated with TNF, we next examined if doxycycline could inhibit TNF-mediated NF- 
$\kappa \mathrm{B}$ activation in these cells. Cells were pretreated with doxycycline for various times and then stimulated with TNF for various times. The amount of phosphorylated $\mathrm{I} \kappa \mathrm{B} \alpha$ was assessed by western blotting. Cell lines that were sensitive to doxycycline treatment (H9, MyLa, Hut78, and $\mathrm{HH}$ ) (Figure $1 \mathrm{~A}-1 \mathrm{D})$, in which NF- $\kappa \mathrm{B}$ was induced after TNF stimulation (Figure 2A), showed decreased levels of $\mathrm{p}-\mathrm{I} \kappa \mathrm{B} \alpha$ after TNF stimulation in the presence of doxycycline (Figure 3A and data not shown). In contrast, the cell lines that were HTLV-1 positive, had constitutively high levels of $\mathrm{p}-\mathrm{I} \kappa \mathrm{B} \alpha$ that were not further inducible by TNF administration (Figure 2B), showed no effect on $\mathrm{p}-\mathrm{I} \kappa \mathrm{B} \alpha$ levels after TNF stimulation with doxycycline pretreatment (Figure 3B). Therefore, the cell lines that were most sensitive to doxycycline killing were those in which NF- $\kappa \mathrm{B}$ was inducible with TNF stimulation. Most interestingly, we show that doxycycline can block NF- $\mathrm{BB}$ by inhibiting the TNF induced phosphorylation of $\mathrm{I} \kappa \mathrm{B} \alpha$. (Figure 3A).

\section{Doxycycline treatment of CTCL cell lines leads to apoptotic cell death}

To determine if dying cells were undergoing programmed cell death after doxycycline treatment, cells were treated with doxycycline and stained with Annexin V and either 7AAD or propidium iodide (PI). Live and dead cells were plotted against Annexin V stains to detect which ones had undergone programmed cell death (Figure 4). Similar to the trypan blue exclusion assay results (Figure 1), doxycycline increased the percentage of late apoptotic cells in a dose dependent manner in $\mathrm{H} 9$, MyLa, HH, and Hut78 CTCL cell lines, while MJ cells were resistant. For example, the percentage of late apoptotic H9 cells
A.

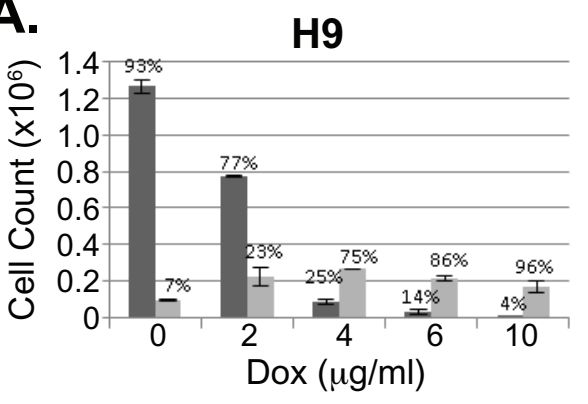

B.

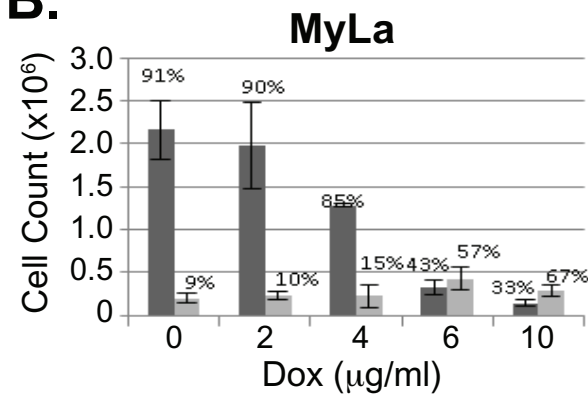

C.

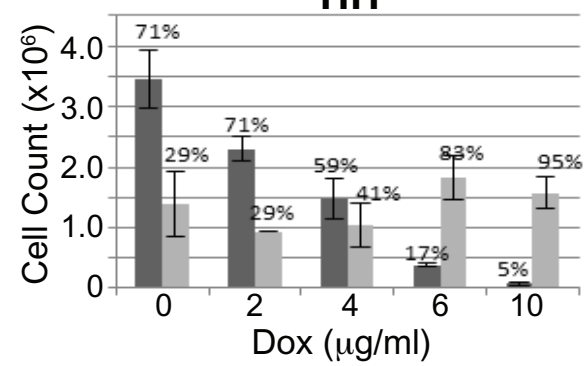

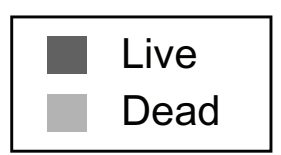

D.

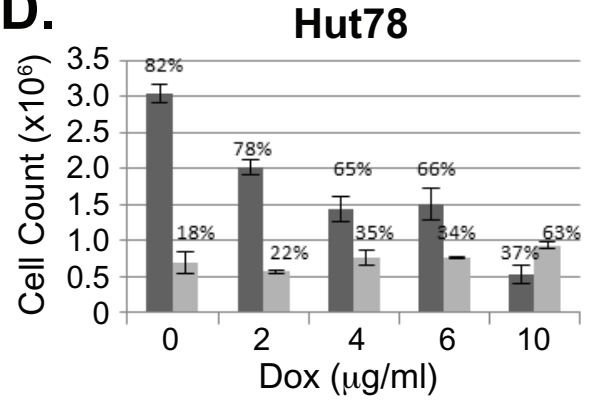

E.

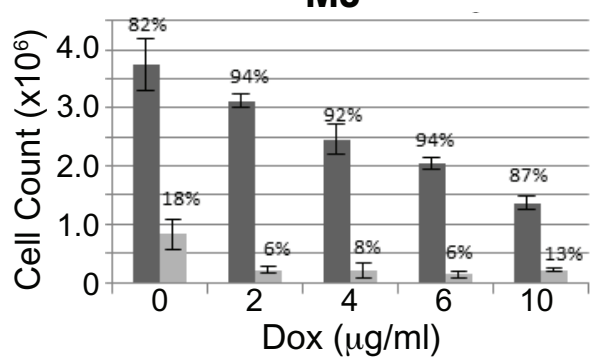

Figure 1: Doxycycline decreases viability of a subset of CTCL cell lines. A-E. CTCL cell lines H9, MyLa, HH, Hut78, and MJ were cultured in the presence or absence of doxycycline (Dox) at the indicated concentrations. After four days of treatment, cell numbers and viability were assessed by light microscopy after staining with trypan blue and total live and dead cell counts were plotted. Error bars represent the standard deviation of duplicate or triplicate measurements. 
increased with increasing doxycycline concentrations, from $2.49 \%$ (untreated) to $14.2 \%(10 \mu \mathrm{g} / \mathrm{mL})$ and $31.3 \%$ $(40 \mu \mathrm{g} / \mathrm{mL})$. Moreover, MJ cells showed little Annexin $\mathrm{V}$ positive dead cells regardless of the doxycycline concentration used.

\section{The extrinsic apoptotic pathway is important in doxycycline killing}

We next examined classic signatures of apoptosis. There are two main pathways of apoptosis, which differ in the way that initiator caspases are activated. The extrinsic pathway is activated through death receptors and the intrinsic pathway acts through the mitochondria [34]. These pathways may act separately or together depending on cell type but eventually converge when effector caspases are activated [35]. This leads to protein cleavage, DNA fragmentation, membrane blebbing, and the formation of apoptotic bodies, which are signature characteristics of apoptosis [36].

Caspase- 8 initiates the extrinsic pathway upon death receptor ligand ligation and activates downstream effector caspases such as caspase-3 [37]. Caspase-3 activation leads to cleavage of PARP-1, a nuclear enzyme involved in DNA damage repair, which is fragmented into multiple catalytic components during apoptosis including the 24KDa and $89 \mathrm{KDa}$ fragments [37-39]. H9 cells treated with doxycycline demonstrated decreased levels of procaspase- 3 and increased cleavage of PARP-1 in a dose dependent manner (Figure 5A), suggesting a potential role for caspase- 8 . To further evaluate if caspase- 8 had a role in the programmed cell death observed in CTCL cells upon treatment with doxycycline, we treated $\mathrm{H} 9$ cells with the caspase- 8 inhibitor, Z-IETD-FMK (Figure 5B). While late apoptosis was observed in $55.63 \%$ of cells treated with doxycycline alone, this decreased to $17.3 \%$ in cells additionally treated with the caspase 8 inhibitor. Collectively, these results show that one mechanism by which doxycycline induces apoptosis in CTCL cell lines is through caspase-8, an initiator to the extrinsic pathway of apoptosis.

\section{The intrinsic apoptotic pathway is important in doxycycline killing}

BCL2 $\alpha$ prevents the production of Reactive Oxygen Species (ROS) at high levels within cells by inhibiting the release of cytochrome $\mathrm{c}$ from the mitochondria [40]. Moreover, BCL2a is an NF- $\kappa \mathrm{B}$ dependent gene [41] that has been shown to be expressed in CTCLs [42-44]. Doxycycline treatment of CTCL cell lines correlated with decreased levels of BCL $2 \alpha$ in a dose dependent manner (Figure 6A). This also correlated with increasing levels of cytochrome $\mathrm{c}$ in the cytoplasm (Figure 6B). These results suggest involvement of the intrinsic pathway of apoptosis in cells treated with doxycycline, likely due to increased levels of ROS.

\section{Apoptosis induced by doxycycline is due to reactive oxygen species}

Studies have shown that stimulation of NF$\kappa \mathrm{B}$ by TNF activates the anti-oxidative defense in T-cells, and that inhibition of this pathway results in excess production of reactive oxygen species $[45,46]$. Additionally, ROS have been shown to induce apoptosis in CTCL cells [47]. Furthermore, a recent study proposed that a global phenotype that is conserved among cancer cells is the dependence on mitochondrial biogenesis for clonal expansion and survival [48]. This study showed that several classes of FDA-approved antibiotics, including tetracyclines, can be used to eradicate
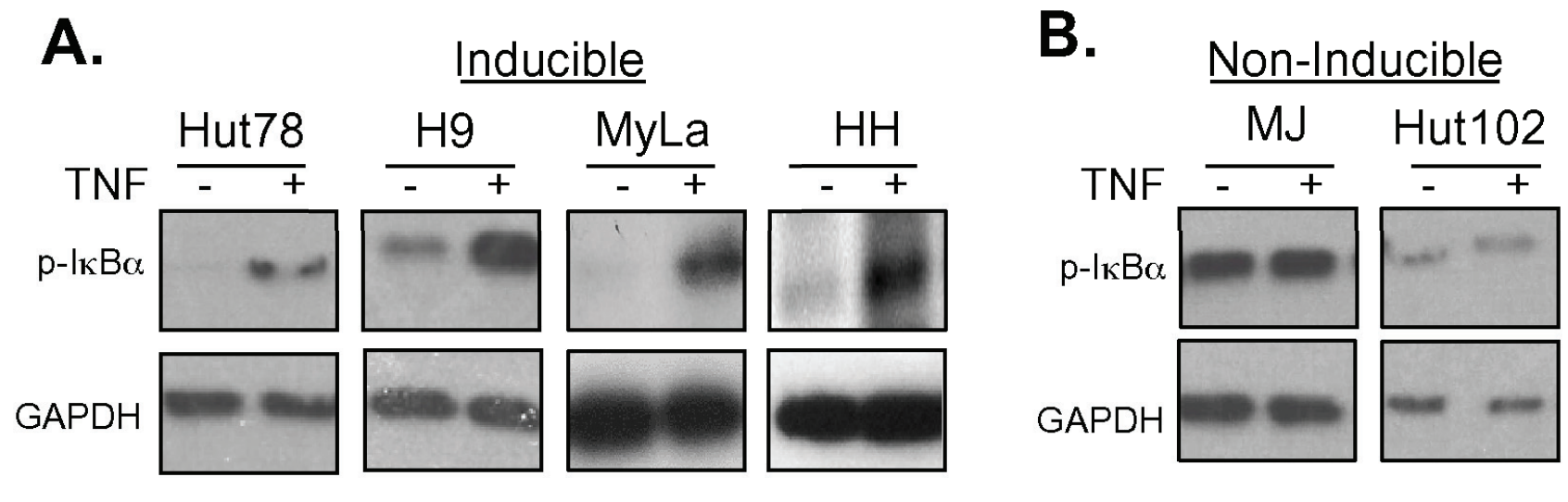

Figure 2: Doxycycline resistant cell lines are resistant to TNF-induced NF- $\mathrm{B}$ pathway activation. A. Cell lines that were sensitive to Dox treatment (Hut78, H9, MyLa and HH) or B. those that were insensitive to Dox treatment (MJ and Hut102) were treated with TNF for 5 or 15 minutes. Whole cell lysates were prepared and resolved in 10\% SDS PAGE gels, electroblotted onto PDVF membranes, and subjected to Western blotting using antibodies specific for $\mathrm{p}$-I $\mathrm{K} \mathrm{B} \alpha$ and GAPDH (loading control). 

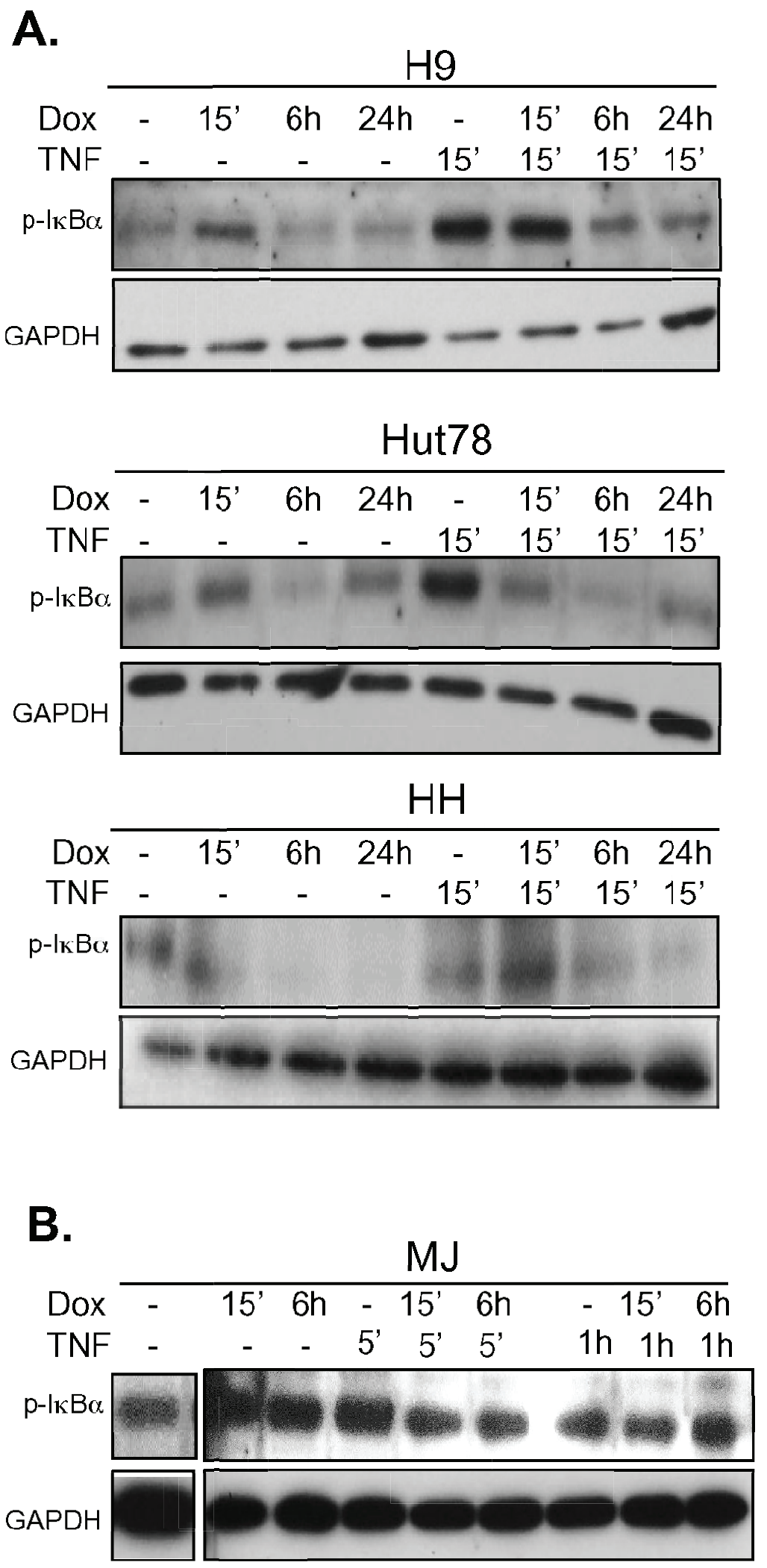

Figure 3: Doxycycline pre-treatment prevents TNF induced phosphorylation of IKB $\alpha$ in doxycycline-sensitive CTCL cell lines. A. CTCL cell lines that are sensitive or B. those that were insensitive to doxycycline were assayed for the effects of doxycycline on TNF signaling to NF- $\mathrm{kB}$. The indicated cell lines were either untreated or pre-treated with doxycycline (Dox, $5 \mu \mathrm{g} / \mathrm{mL})$ for the indicated period of time up to $24 \mathrm{~h}$. Cells were then either left untreated or treated with TNF as indicated. Whole cell lysates were prepared and resolved in 10\% SDS PAGE gels, electroblotted onto PDVF membranes, and protein levels of p-IKB $\alpha$ and GAPDH (loading control) were assessed using specific antibodies. 
cancer stem cells because they target the mitochondria. Mitochondria are the primary site for the production of ROS within cells and the resulting oxidative stress plays a very important role in apoptosis [49]. Due to the fact that our data suggested that ROS was important in apoptotic death induced by doxycycline in CTCL cells (Figure 6A and 6B), we next examined if inhibition of ROS could rescue cells from apoptosis. H9 and MyLa were incubated with catalase or flavoprotein inhibitor diphenyleneiodonium (DPI), both of which block mitochondria-derived ROS production [50]. Catalase catalyzes the breakdown of hydrogen peroxide into oxygen and water. As shown in Figure 6C and 6D, catalase and DPI significantly reduced the killing effect of doxycycline. In summary, our results indicate that doxycycline induced apoptosis is mediated through both the intrinsic and extrinsic pathways of apoptosis.

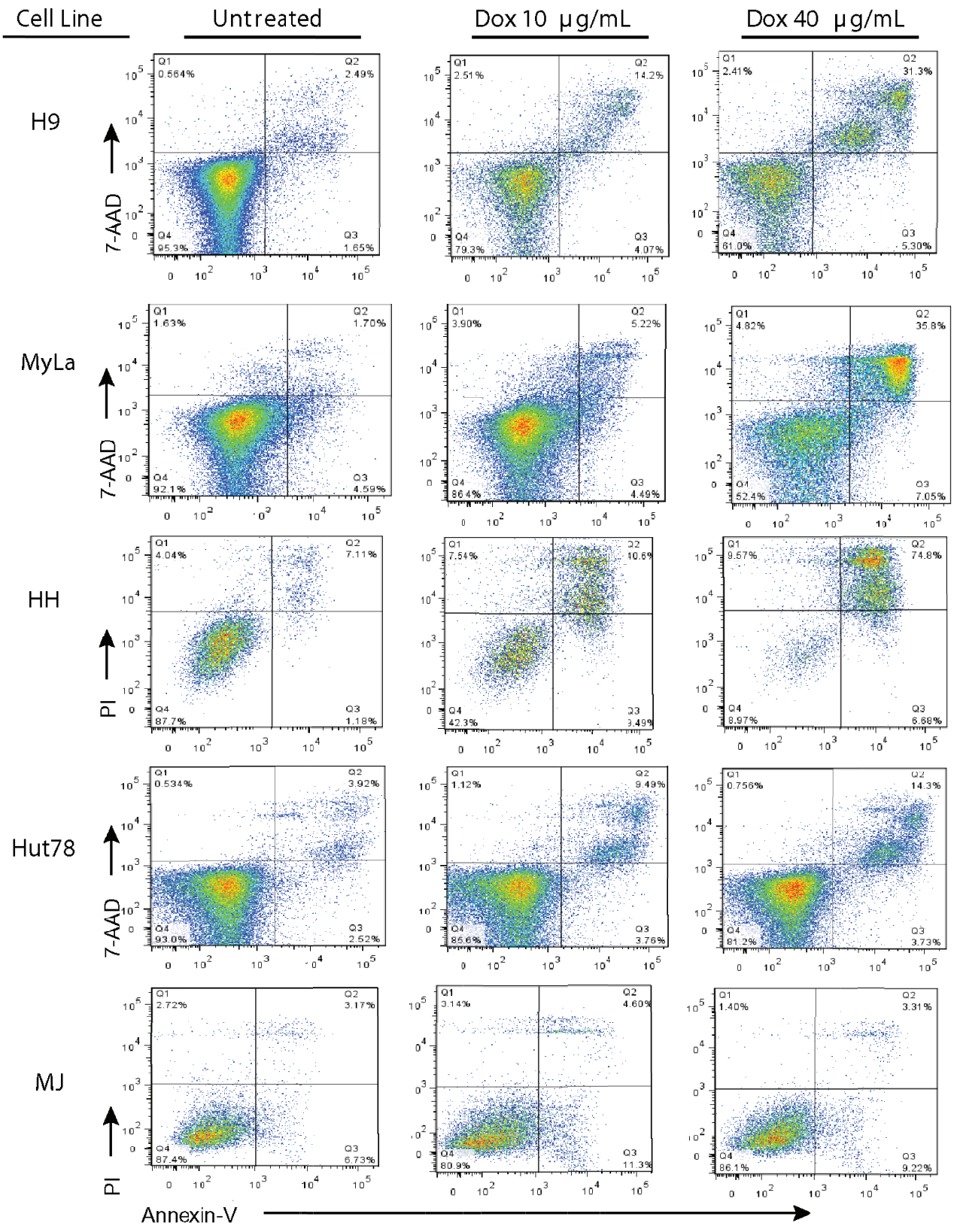

Figure 4: Doxycycline induces programmed cell death in sensitive CTCL cell lines. Doxycycline sensitive (H9, MyLa, HH, and Hut78) and insensitive (MJ) CTCL cell lines were either untreated or treated with the specified concentrations of Doxycycline (10 $\mu$ g/ $\mathrm{mL}$ or $40 \mu \mathrm{g} / \mathrm{mL}$ ) for 48 hours (H9, MyLa, and HH) or 96 hours (Hut78 and MJ). Treated cells were then stained with PI or 7AAD and PE-Annexin V, and analyzed by flow cytometry. 


\section{Doxycycline kills primary malignant T-cells from a patient with Sézary Syndrome}

To see if doxycycline would induce apoptosis in primary cells, CD4+ T cells from a patient with Sézary Syndrome were treated with doxycycline. The patient was a 68 year old male, who presented with erythroderma. His flow cytometry showed that $65.72 \%$ of all lymphocytes were CD4+CD26-, $10.95 \%$ were CD4+CD7-, and that the CD4+/CD8+ ratio was 24.33. Trypan blue exclusion assays showed that $\mathrm{CD} 4+\mathrm{T}$-cells from this patient were killed by doxycycline in a dose dependent manner (Figure 7A). Additionally, after 48 hours of treatment with doxycycline $40 \mu \mathrm{g} / \mathrm{mL}, 26.1 \%$ of the untreated cells were late apoptotic, while $85.8 \%$ of cells treated with doxycycline had died through apoptosis (Figure 7B). This was consistent over several blood draws from different dates. (Data not shown) A second subject with SS also showed decreased CD4+ T-cell viability upon doxycycline treatment (results not shown). Lastly, blood samples from a healthy individual showed that only $11.3 \%$ of T-cells underwent apoptosis
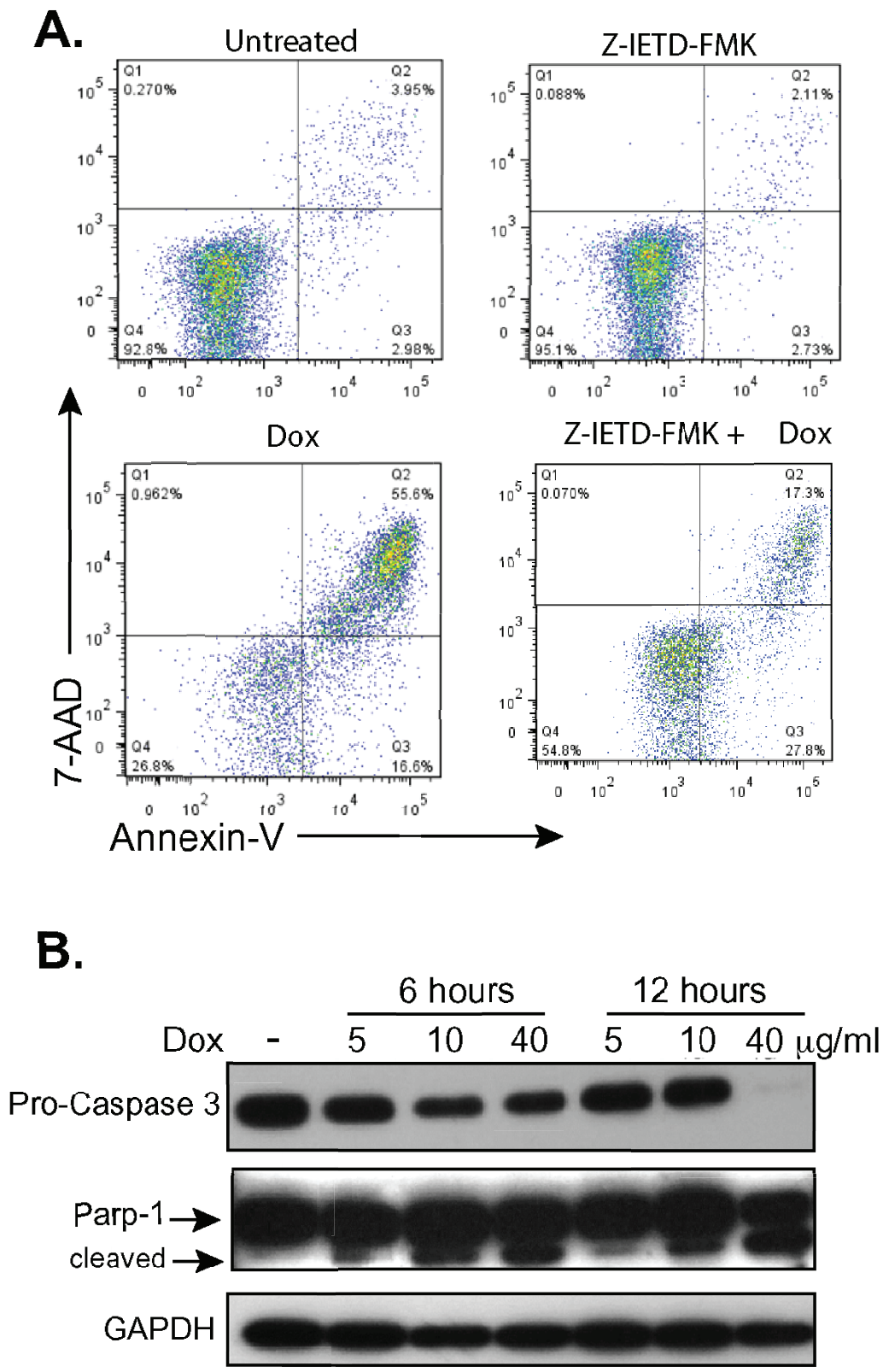

Figure 5: Doxycycline affects the extrinsic pathway of apoptosis. A. H9 cells were treated with or without doxycycline (Dox, $10 \mu \mathrm{g} / \mathrm{mL}$ ) and/or the caspase-8 inhibitor Z-IETD-FMK for 48 hours, stained with 7AAD and PE-Annexin V, and analyzed by flow cytometry. B. Western blots of whole cell lysates from $\mathrm{H} 9$ cells treated with doxycycline (Dox) at specified concentrations and timepoints show decreasing levels of pro-caspase 3 and formation of the $89 \mathrm{KDa}$ fragment of PARP-1 (cleaved). GAPDH levels were assessed as a loading control. 
after 48 hours of doxycycline treatment, which was similar to untreated control (Figure 7C).

\section{DISCUSSION}

Although doxycycline induces apoptosis in most CTCL cell lines examined, two subgroups respond to treatment differently, and this response correlated with doxycycline's ability to inhibit phosphorylation of $\mathrm{I} \kappa \mathrm{B} \alpha$. The group that was sensitive to $\mathrm{TNF} \alpha$ stimulation responded to doxycycline treatment, whereas the group that was insensitive, remained resistant. The fact that some cells could not be induced with TNF could explain why some CTCL patients might respond to therapies that inhibit NF- $\kappa \mathrm{B}$, such as bortezomib, while others do not. Indeed, previous studies have found a wide range of sensitivity of CTCL cells to NF- $\kappa B$ inhibition [47].

It is important to note that in our study those cells that were insensitive to TNF $\alpha$ stimulation and resistant to doxycycline, MJ and Hut102 cells, were HTLV-1
A.

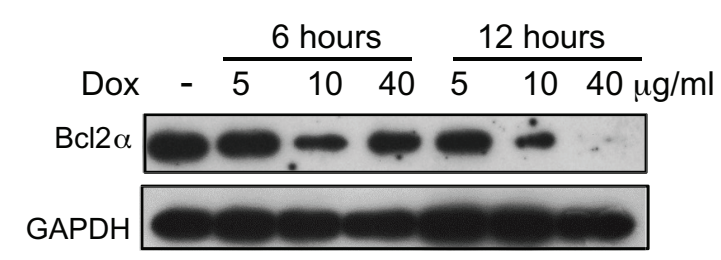

B.

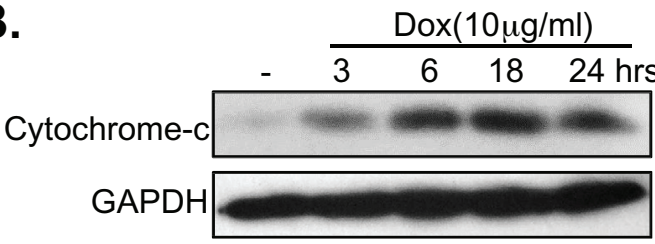

D.

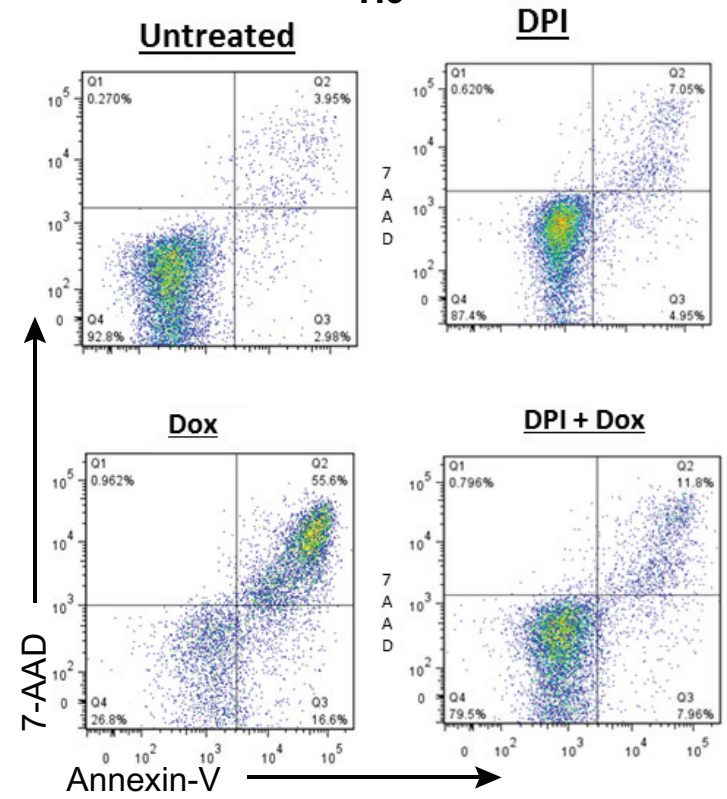

C.

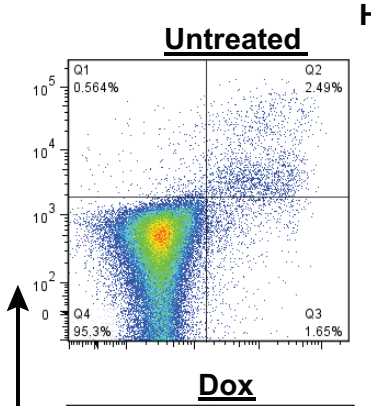

H9
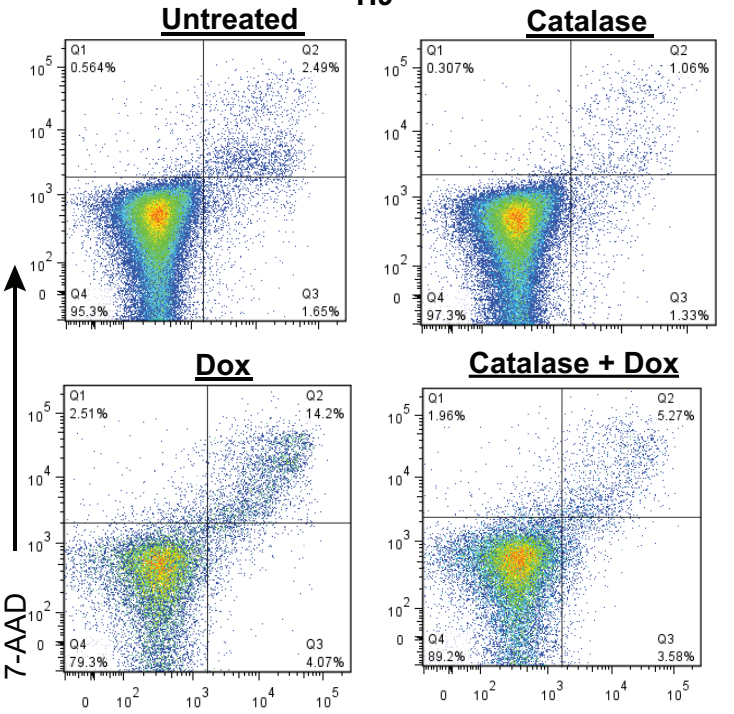

Catalase + Dox

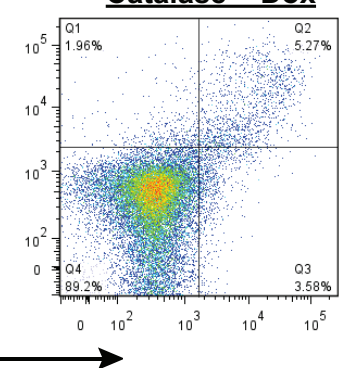

Figure 6: Doxycycline affects the intrinsic pathway of apoptosis. A. and B. H9 cells were either untreated or treated with doxycycline (Dox) at the specified times and concentrations. A. Western blot analysis of cytoplasmic extracts for the NF- $\kappa \mathrm{B}$ dependent, anti-apoptotic protein BCL2 $\alpha$. B. Cytoplasmic levels of cytochrome C were assessed by Western blotting. C. and D. Reversal of doxycycline induced apoptosis by ROS inhibition was assessed. H9 cells were untreated or treated with $10 \mu \mathrm{g} / \mathrm{ml}$ doxycycline for 48 hours and apoptosis was assessed by flow cytometric analysis of 7AAD and PI staining. The effects of ROS inhibition were assessed by co-treating with either C. catalase, or D. diphenyleneiodonium chloride (DPI). 

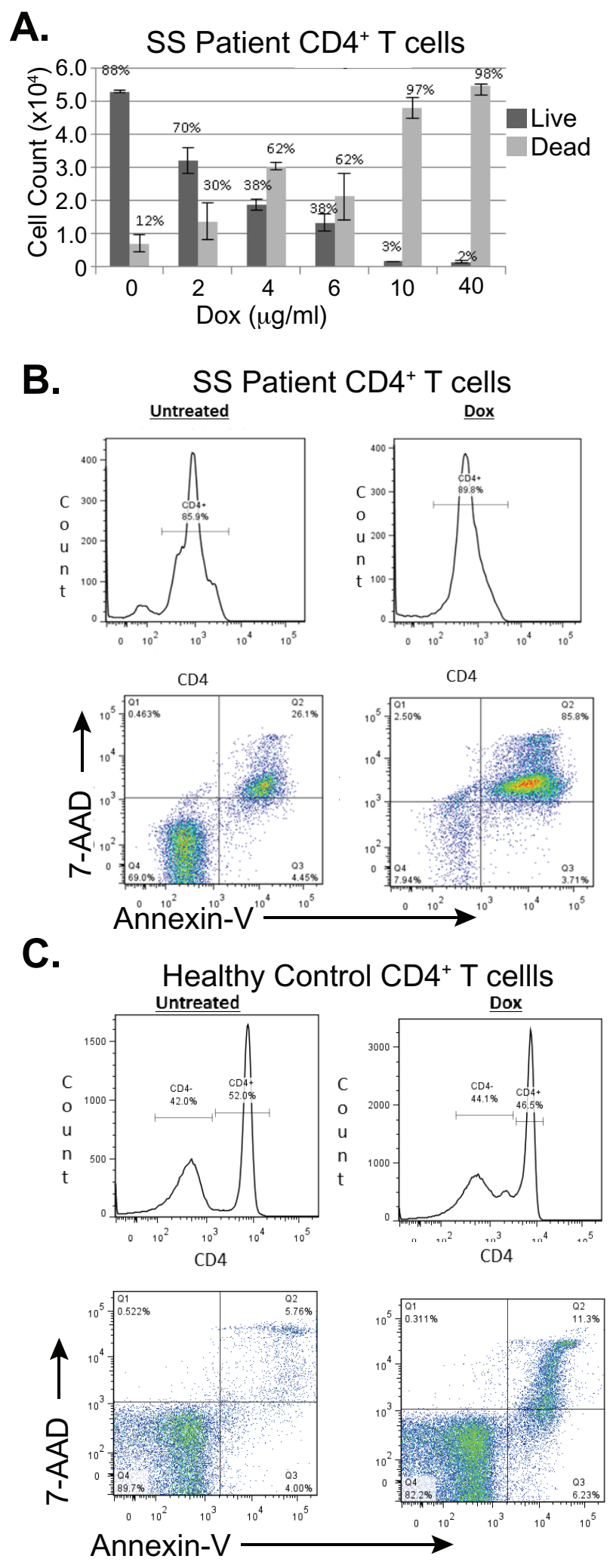

Figure 7: Doxycycline induces programmed cell death in primary CD4+ T-cells from a subject with Sézary Syndrome but not in those from a healthy subject. A. Total $\mathrm{CD}^{+} \mathrm{T}$ cells from a patient with $\mathrm{SS}$ were treated ex vivo with the indicated concentrations of doxycycline (Dox) for 96 hours. Cell Viability was assessed using Trypan blue exclusion and total numbers of live and dead cells were plotted. Error bars represent the standard deviation of triplicate measurements. B. C. Flow cytometry was used to assess cell death in B. CD4+ primary Sézary Cells B. and CD4+ healthy cells C., which were stained with FITC-CD4, 7AAD and PE-Annexin V after either being untreated or treated with doxycycline (Dox, $40 \mu \mathrm{g} / \mathrm{mL})$ for 48 hours. 
infected. HTLV-1 induces constitutive activation of NF$\kappa \mathrm{B}$ through Tax [33]. Tax is a viral protein that binds directly to the regulatory subunit of the kinase that phosphorylates I $\mathrm{B} \alpha$, IKK. Thereafter, IKK constitutively activates IKK $\alpha$ and IKK $\beta$ causing degradation of I $\mathrm{BS}$, driving activation of both classical and alternative NF$\kappa \mathrm{B}$ pathways [51]. Furthermore, HTLV Tax also exerts multiple effects on NF- $\kappa \mathrm{B}$-dependent and -independent transcriptional events in infected cells. Given that MJ and Hut102 cell lines were insensitive to doxycycline, we speculate that doxycycline is unable to fully repress $\mathrm{NF}-\kappa \mathrm{B}$, as well as other Tax-induced transcriptional events. However, given that in patients, CTCL cells are rarely infected with HTLV-1, it is unclear that this finding would significantly impact the potential clinical utility of doxycycline in CTCL treatment.

Consistent with these findings, our results show that doxycycline can target both Mycosis Fungoides and Sézary Syndrome cells. Doxycycline induces cell death through the activation of caspase- 8 and the release of cytochrome c, suggesting the involvement of both the extracellular and intracellular pathways of apoptosis. Furthermore, doxycycline's ability to induce apoptosis in CTCL cells can be reversed through the inhibition of ROS. Treatment with oxidants has been shown to be sufficient when treating inflammatory conditions in which NF- $\kappa B$ is constitutively active [52]. Through the inhibition of NF$\kappa \mathrm{B}$, as shown by inhibition of $\mathrm{I} \kappa \mathrm{B} \alpha$ phosphorylation and decreased BCL2 $\alpha$ levels, doxycycline increased ROS in CTCL cells and triggered apoptosis that could be reversed through treatment with antioxidants such as catalase and DPI.

Our results are interesting in light of a recent case study of a 21 year old female with a 5 year history of CTCL, primary cutaneous small/medium, pleomorphic CD4+ T cell lymphoma, who achieved a 13 month complete remission through oral treatment with doxycycline monohydrate at a dose of $200 \mathrm{mg}$ per day [53]. Moreover, the idea that antibiotics could be used to target a conserved weak point among different cancers was recently suggested by Lamb et al; implying that doxycycline could be used to treat other types of cancers as well [48]. We have already shown that doxycycline can also induce apoptosis in diffuse large B-cell lymphoma cell lines [20]. Additionally another study independently suggested that doxycycline could be used as a therapy in other cancers [54]. Two additional studies have shown a potential role for doxycycline in the mammosphereforming activity in breast cancers $[55,56]$. Wan et al showed that doxycycline, in combination with aspirin, lysine, and mifepristone can prevent and treat cancer metastasis [57]. Qin et al showed that doxycycline suppressed proliferation and metastasis of lung cancer cells [58]. These promising results combined with our data, warrant further clinical trials on the efficacy of doxycycline in the treatment of these cancers. A clinical trial to study the efficacy and safety of doxycycline in patients with relapsed CTCL is underway [59]. Further study will identify the chemical components of doxycycline that make it a lymphoma killer.

\section{MATERIALS AND METHODS}

\section{Tissue culture}

MyLa cells were kindly provided by Andrew Feldman, M.D., from Mayo Clinic in Rochester, MN. Other cell lines were obtained through the American Tissue Culture Collection. H9, MyLa, HH, and primary T-cells were kept between $3 \times 10^{5}-1 \times 10^{6}$ cells $/ \mathrm{mL}$ in RPMI media (Gibco) supplemented with 10\% Fetal Bovine Serum (FBS, Gibco) and 1\% Penicillin and Streptomycin (Gibco). MJ and Hut78 cell lines were grown in DMEM (Gibco) supplemented with 20\% FBS and 1\% Penicillin and Streptomycin. Cells were incubated at $37^{\circ} \mathrm{C}$ with $5 \%$ $\mathrm{CO}_{2}$.

\section{Doxycycline stock}

Doxycycline hyclate (Sigma Aldrich,) stock solutions were made at $40 \mathrm{mg} / \mathrm{mL}$ or $10 \mathrm{mg} / \mathrm{mL}$ in water. A conversion factor of $93.76 \%$ was used to account for the hyclate. Samples were aliquoted into Eppendorf tubes and stored at $-20^{\circ} \mathrm{C}$ protected from light. Stock solutions were diluted to final concentrations with medium.

\section{Trypan blue assays}

Cells from pre-established cell lines were plated at $3 \times 10^{5}$ cells $/ \mathrm{mL}$ in 12 well plates and treated with doxycycline using the indicated concentrations. Primary cells were plated at $5 \times 10^{5}$ cells $/ \mathrm{mL}$ in 96 well round bottom plates. Cell viability was measured by adding a 1:1 trypan blue: cell sample solution onto a hemocytometer. Trypan blue was obtained from GIBCO.

\section{Mitochondrial and cytoplasmic extracts}

Cytoplasmic extracts were separated from mitochondria using digitonin fractionation. Briefly, H9 cells were collected, washed with PBS, and resuspended in cytosolic lysis buffer $(250 \mathrm{mM}$ Sucrose, $70 \mathrm{mM} \mathrm{KCl}$, 200ug/mL digitonin (Cayman), and protease inhibitor (Pierce Thermo Scientific). After confirming that $>95 \%$ of cells had lysed by trypan blue, these were centrifuged at $1,000 \times \mathrm{g}$ for 5 minutes at $4^{\circ} \mathrm{C}$. Supernatant was collected as the cytoplasmic fraction. The pellet was washed with PBS, and incubated for 10 minutes at $4^{\circ} \mathrm{C}$ in mitochondrial lysis buffer $(50 \mathrm{mM}$ Tris $\mathrm{HCl}$ p.H. $7.4,150 \mathrm{mM} \mathrm{NaCl}$, 2mM EDTA, 2mM EGTA, and 0.2\% Triton X-100, 0.3\% NP-40, plus protein inhibitor (Pierce Thermo Scientific)). The suspension was centrifuged at $10,000 \mathrm{x} \mathrm{g}$ for 10 
minutes and the supernatant collected as the mitochondrial fraction.

\section{Whole cell lysates}

Cells treated with doxycycline for specific times were removed from the incubator, collected on ice, pelleted and washed with cold $\left(4^{\circ} \mathrm{C}\right) \mathrm{PBS}$. The pellet was resuspended in RIPA buffer (1X PBS, 1\% Nonidet P-40, 0.5\% Sodium Dodecyl Sulfate (SDS)) with 1:100 Halt Protease and Phosphatase inhibitor (Pierce Thermo Scientific)). Protein concentration was determined using BioRad's DC Protein Assay according to manufacturer's instructions. Samples were stored at $-80^{\circ} \mathrm{C}$.

\section{Western blot analysis}

Protein lysates $(20-25 \mu \mathrm{g})$ were denatured using 1X Laemmli Buffer and run on $7.5,10$, or $16 \%$ SDS PAGE gels at $100 \mathrm{~V}$ for about 2 hours. Proteins were then transferred onto a PDVF membrane (BioRad or Thermo Fisher Scientific) at $100 \mathrm{~V}$ for 1 hour. Ponceau-S staining was done to verify transfer. Non-specific binding was blocked by incubating the membrane for at least one hour at room temperature or overnight at $4^{\circ} \mathrm{C}$ in $5 \%$ milk in TBS for non-phosphorylated proteins, or 5\% Bovine serum albumin (BSA Fraction V, Fisher Scientific) in TBS for phosphorylated proteins. The membrane was then blotted with primary antibody diluted in 5\% BSA or Milk in TBS supplemented with $0.1 \%$ Tween 20 (TBST). After an overnight incubation at $4^{\circ} \mathrm{C}$, the membrane was washed with TBST and incubated in the secondary antibody for at least 2 hours at room temperature in 5\% BSA or Milk in TBST. After washing out the secondary antibody in TBST, the membrane was exposed to BioRad's Clarity Western ECL substrate according to manufacturer's instructions. Signal was detected using UltraCruz Autoradiography Film (Santa Cruz Biotech). Antibodies for GAPDH and $\mathrm{p}-\mathrm{I} \kappa \mathrm{B} \alpha$ were obtained from Cell Signaling (Catalog \# 14C10 and 14D4, respectively). BCL2 $\alpha$, Pro-caspase 3, PARP-1, and cytochrome c antibodies were obtained from Santa Cruz Biotech Catalog \# SC-7382, SC-7148, SC8007, and SC-271627, respectively.

\section{Apoptosis assay, flow cytometry}

Cells were stained with PE-Annexin V (BD Pharmingen Apoptosis kit) and either 7AAD (BD) or PI (Research Organics). Selection of CD4+ in primary T-cells was performed concurrently with Annexin V stains using BioLegend's FITC tagged antibody

\section{PBMC isolation}

Peripheral blood was obtained after subjects signed consent approved by the University of Rochester's Research Subject Review Board (RSRB No. 46521).
Whole blood was collected in $6 \mathrm{ml}$ BD Vacutainer $\AA$ plastic tubes with EDTA, and processed no longer than an hour after collection time. Samples remained at room temperature until they were processed. Whole blood was mixed with an equal volume of PBS and layered on top of Ficoll-Hypaque PLUS(GE)for isolation of peripheral blood mononuclear cells (PBMC) and centrifuged at $400 \mathrm{x} g$ for 40 minutes with no break. PBMC was then washed three times with PBS and CD4+ cells were negatively selected using the CD4+ Human T-cell isolation kit (Miltenyi Biotech). Cells were incubated at a concentration of $5 \times 10^{5}$ cells $/ \mathrm{mL}$ in round bottom 96 well plates overnight and then treated with doxycycline.

\section{Reactive oxygen species assays}

H9 Cells were treated with diphenyleneiodonium chloride (Cayman) at $0.1 \mu \mathrm{g} / \mathrm{mL}, 0.5 \mu \mathrm{g} / \mathrm{mL}$ and $1 \mu \mathrm{g} / \mathrm{mL}$ or Catalase (Sigma Aldrich) at $200 \mu \mathrm{g} / \mathrm{mL}$, with doxycycline at $10 \mu \mathrm{g} / \mathrm{mL}$ for 48 hours. Apoptosis assay using Annexin $\mathrm{V}$ and 7AAD was done as described above.

\section{Caspase 8 inhibition}

Inhibitor Z-IETD-FMK (BD Pharmingen) was added at 2 and $20 \mu \mathrm{g} / \mathrm{mL}$, incubated at $37^{\circ} \mathrm{C}$ with $5 \%$ Carbon Dioxide for an hour and then treated with Doxycycline at $10 \mathrm{ug} / \mathrm{mL}$ for 48 hours. Annexin V and 7AAD stains were then done as described above.

\section{TNF stimulation}

Cells were stimulated with human recombinant TNF at $10 \mathrm{ng} / \mathrm{mL}$ for the indicated times at $37^{\circ} \mathrm{C}$, collected on ice, washed with cold PBS once, and lysed for protein isolation. Lysates were stored at $-80^{\circ} \mathrm{C}$ until further processing.

\section{ACKNOWLEDGMENTS}

We would like to thank Dr. Andrew Feldman for kindly providing MyLa cells for the conduct of this study.

\section{CONFLICTS OF INTEREST}

All of the authors report no relevant conflicts of interest regarding this manuscript and study.

\section{GRANT SUPPORT}

BP and CA were funded by the Rochester General Hospital Skin Disease Research Fund and BP was funded by the James P. Wilmot Cancer Fellowship. 


\section{REFERENCES}

1. The Surveillance E, and End Results (SEER) Program. (2015). SEER Cancer Statistics Review 1975-2012. Non-Hodkin's Lymphoma: Incidence Rates, and APC, Lymphoma Subtypes, Both Sexes: National Cancer Institute).

2. Olsen E, Vonderheid E, Pimpinelli N, Willemze R, Kim Y, Knobler R, Zackheim H, Duvic M, Estrach T, Lamberg S, Wood G, Dummer R, Ranki A, et al. Revisions to the staging and classification of mycosis fungoides and Sezary syndrome: a proposal of the International Society for Cutaneous Lymphomas (ISCL) and the cutaneous lymphoma task force of the European Organization of Research and Treatment of Cancer (EORTC). Blood. 2007; 110:1713-1722.

3. Kim YH, Liu HL, Mraz-Gernhard S, Varghese A, Hoppe RT. Long-term outcome of 525 patients with mycosis fungoides and sézary syndrome: Clinical prognostic factors and risk for disease progression. Archives of Dermatology. 2003; 139:857-866.

4. Quaglino P, Pimpinelli N, Berti E, Calzavara-Pinton P, Alfonso Lombardo G, Rupoli S, Alaibac M, Bottoni U, Carbone A, Fava P, Fimiani M, Mamusa AM, Titli S, Zinzani PL, Bernengo MG and on behalf of the Gruppo Italiano Linfomi C. Time course, clinical pathways, and long-term hazards risk trends of disease progression in patients with classic mycosis fungoides. Cancer. 2012; 118:5830-5839.

5. Scarisbrick JJ, Kim YH, Whittaker SJ, Wood GS, Vermeer MH, Prince HM, Quaglino P. Prognostic factors, prognostic indices and staging in mycosis fungoides and Sezary syndrome: where are we now? The British journal of dermatology. 2014; 170:1226-1236.

6. Clark RA, Watanabe R, Teague JE, Schlapbach C, Tawa MC, Adams N, Dorosario AA, Chaney KS, Cutler CS, Leboeuf NR, Carter JB, Fisher DC, Kupper TS. Skin effector memory $\mathrm{T}$ cells do not recirculate and provide immune protection in alemtuzumab-treated CTCL patients. Sci Transl Med. 2012; 4:117ra7.

7. Rodd AL, Ververis K, Karagiannis TC. Current and Emerging Therapeutics for Cutaneous T-Cell Lymphoma: Histone Deacetylase Inhibitors. Lymphoma. 2012; 2012:10.

8. Duvic M, Martin AG, Olsen EA, Fivenson DP, Prince HM. Efficacy and safety of denileukin diftitox retreatment in patients with relapsed cutaneous T-cell lymphoma. Leukemia \& lymphoma. 2013; 54:514-519.

9. Duvic M, Hymes K, Heald P, Breneman D, Martin AG, Myskowski P, Crowley C, Yocum RC. Bexarotene is effective and safe for treatment of refractory advanced-stage cutaneous T-cell lymphoma: multinational phase II-III trial results. Journal of clinical oncology. 2001; 19:2456-2471.

10. Horwitz SM, Kim YH, Foss F, Zain JM, Myskowski PL, Lechowicz MJ, Fisher DC, Shustov AR, Bartlett NL,
Delioukina ML, Koutsoukos T, Saunders ME, O'Connor OA, Duvic M. Identification of an active, well-tolerated dose of pralatrexate in patients with relapsed or refractory cutaneous T-cell lymphoma. Blood. 2012; 119:4115-4122.

11. Whittaker SJ, Demierre MF, Kim EJ, Rook AH, Lerner A, Duvic M, Scarisbrick J, Reddy S, Robak T, Becker JC, Samtsov A, McCulloch W, Kim YH. Final results from a multicenter, international, pivotal study of romidepsin in refractory cutaneous T-cell lymphoma. Journal of clinical oncology. 2010; 28:4485-4491.

12. Hughes CF, Khot A, McCormack C, Lade S, Westerman DA, Twigger R, Buelens O, Newland K, Tam C, Dickinson M, Ryan G, Ritchie D, Wood C, Prince HM. Lack of durable disease control with chemotherapy for mycosis fungoides and Sezary syndrome: a comparative study of systemic therapy. Blood. 2015; 125:71-81.

13. Prichard M, Harris T, Williams ME, Densmore JJ. Treatment strategies for relapsed and refractory aggressive nonHodgkin's lymphoma. Expert opinion on pharmacotherapy. 2009; 10:983-995.

14. Lamb J. The Connectivity Map: a new tool for biomedical research. Nat Rev Cancer. 2007; 7:54-60.

15. Oeckinghaus A, Ghosh S. The NF-kappaB family of transcription factors and its regulation. Cold Spring Harbor perspectives in biology. 2009; 1:1-14.

16. Davis RE, Brown KD, Siebenlist U, Staudt LM. Constitutive Nuclear Factor $\kappa \mathrm{B}$ Activity Is Required for Survival of Activated B Cell-like Diffuse Large B Cell Lymphoma Cells. The Journal of Experimental Medicine. 2001; 194:1861-1874.

17. Karin M. NF- $\kappa \mathrm{B}$ as a Critical Link Between Inflammation and Cancer. Cold Spring Harbor perspectives in biology. 2009; 1:1-14.

18. Sors A, Jean-Louis F, Pellet C, Laroche L, Dubertret L, Courtois G, Bachelez H, Michel L. Down-regulating constitutive activation of the NF-kappaB canonical pathway overcomes the resistance of cutaneous T-cell lymphoma to apoptosis. Blood. 2006; 107:2354-2363.

19. Zheng Y, Vig M, Lyons J, Van Parijs L, Beg AA. Combined Deficiency of p50 and cRel in CD4+ T Cells Reveals an Essential Requirement for Nuclear Factor $\kappa \mathrm{B}$ in Regulating Mature T Cell Survival and In Vivo Function. The Journal of Experimental Medicine. 2003; 197:861-874.

20. Pulvino M, Chen L, Oleksyn D, Li J, Compitello G, Rossi R, Spence S, Balakrishnan V, Jordan C, Poligone B, Casulo C, Burack R, Shapiro JL, et al. Inhibition of COP9signalosome (CSN) deneddylating activity and tumor growth of diffuse large B-cell lymphomas by doxycycline. Oncotarget. 2015; 6:14796-14813. doi: 10.18632/ oncotarget.4193.

21. Migliardi JR, Schach von Wittenau M. (1967). Pharmacokinetic properties of doxycycline in man. Fifth 
International Congress of Chemotherapy Proceedings, pp. 165-171.

22. Griffin MO, Fricovsky E, Ceballos G, Villarreal F. Tetracyclines: a pleitropic family of compounds with promising therapeutic properties. Review of the literature. American journal of physiology Cell physiology. 2010; 299:C539-548.

23. Bahrami F, Morris DL, Pourgholami MH. Tetracyclines: drugs with huge therapeutic potential. Mini Rev Med Chem. 2012; 12:44-52.

24. Golub LM. Introduction and background. Pharmacological research. 2011; 63:99-101.

25. Caton J, Ryan ME. Clinical studies on the management of periodontal diseases utilizing subantimicrobial dose doxycycline (SDD). Pharmacological research. 2011; 63:114-120.

26. Griffith KS, Lewis LS, Mali S, Parise ME. Treatment of malaria in the united states: A systematic review. JAMA. 2007; 297:2264-2277.

27. Kirtschig G, Khumalo N. Management of Bullous Pemphigoid. Am J Clin Dermatol. 2004; 5:319-326.

28. Smith K, Leyden JJ. Safety of doxycycline and minocycline: A systematic review. Clinical Therapeutics. 2005; 27:1329-1342.

29. Baldwin AS, Jr. The NF-kappa B, I kappa B proteins: new discoveries and insights. Annu Rev Immunol. 1996; 14:649-683.

30. Ghosh S, May MJ, Kopp EB. NF-kappa B and Rel proteins: evolutionarily conserved mediators of immune responses. Annu Rev Immunol. 1998; 16:225-260.

31. Hayden MS, Ghosh S. Signaling to NF-kappaB. Genes Dev. 2004; 18:2195-2224.

32. Compagno M, Lim WK, Grunn A, Nandula SV, Brahmachary M, Shen Q, Bertoni F, Ponzoni M, Scandurra M, Califano A, Bhagat G, Chadburn A, DallaFavera R, Pasqualucci L. Mutations of multiple genes cause deregulation of NF-kappaB in diffuse large B-cell lymphoma. Nature. 2009; 459:717-721.

33. Currer R, Van Duyne R, Jaworski E, Guendel I, Sampey G, Das R, Narayanan A, Kashanchi F. HTLV tax: a fascinating multifunctional co-regulator of viral and cellular pathways. Frontiers in microbiology. 2012; 3:406.

34. Elmore S. Apoptosis: A Review of Programmed Cell Death. Toxicologic Pathology. 2007; 35:495-516.

35. Igney FH, Krammer PH. Death and anti-death: tumour resistance to apoptosis. Nat Rev Cancer. 2002; 2:277-288.

36. Ziegler U, Groscurth P. Morphological Features of Cell Death. Physiology. 2004; 19:124-128.

37. Thorburn A. Death receptor-induced cell killing. Cellular Signalling. 2004; 16:139-144.

38. D'Amours D, Sallmann FR, Dixit VM, Poirier GG. Gain-offunction of poly(ADP-ribose) polymerase-1 upon cleavage by apoptotic proteases: implications for apoptosis. J Cell Sci. 2001; 114:3771-3778.

39. Jänicke RU, Sprengart ML, Wati MR, Porter AG. Caspase-3 Is Required for DNA Fragmentation and Morphological Changes Associated with Apoptosis. Journal of Biological Chemistry. 1998; 273:9357-9360.

40. Yang J, Liu X, Bhalla K, Kim CN, Ibrado AM, Cai J, Peng T-I, Jones DP, Wang X. Prevention of Apoptosis by Bcl2: Release of Cytochrome c from Mitochondria Blocked. Science. 1997; 275:1129-1132.

41. Catz SD, Johnson JL. Transcriptional regulation of bcl-2 by nuclear factor kappa B and its significance in prostate cancer. Oncogene. 2001; 20:7342-7351.

42. Dummer R, Michie SA, Kell D, Gould JW, Haeffner AC, Smoller BR, Warnke RA, Wood GS. Expression of bcl-2 protein and Ki-67 nuclear proliferation antigen in benign and malignant cutaneous T-cell infiltrates. Journal of cutaneous pathology. 1995; 22:11-17.

43. Garatti SA, Roscetti E, Trecca D, Fracchiolla NS, Neri A, Berti E. (1995). bcl-1, bcl-2, p53, c-myc, and lyt-10 Analysis in Cutaneous Lymphomas. In: Garbe C, Schmitz S and Orfanos CE, eds. Skin Cancer: Basic Science, Clinical Research and Treatment. (Berlin, Heidelberg: Springer Berlin Heidelberg), pp. 249-261.

44. Kanavaros P, Ioannidou D, Tzardi M, Datseris G, Katsantonis J, Delidis G, Tosca A. Mycosis fungoides: Expression of C-myc p62 p53, bcl-2 and PCNA Proteins and Absence of Association with Epstein-Barr Virus. Pathology - Research and Practice. 1994; 190:767-774.

45. Bubici C, Papa S, Pham CG, Zazzeroni F, Franzoso G. The NF-kappaB-mediated control of ROS and JNK signaling. Histol Histopathol. 2006; 21:69-80.

46. Kamata H, Honda S, Maeda S, Chang L, Hirata H, Karin M. Reactive oxygen species promote TNFalpha-induced death and sustained JNK activation by inhibiting MAP kinase phosphatases. Cell. 2005; 120:649-661.

47. Kiessling MK, Klemke CD, Kamiński MM, Galani IE, Krammer PH, Gülow K. Inhibition of Constitutively Activated Nuclear Factor- $\kappa \mathrm{B}$ Induces Reactive Oxygen Species- and Iron-Dependent Cell Death in Cutaneous T-Cell Lymphoma. Cancer Research. 2009; 69:2365-2374.

48. Lamb R, Ozsvari B, Lisanti CL, Tanowitz HB, Howell A, Martinez-Outschoorn UE, Sotgia F, Lisanti MP. Antibiotics that target mitochondria effectively eradicate cancer stem cells, across multiple tumor types: treating cancer like an infectious disease. Oncotarget. 2015; 6:4569-4584. doi: 10.18632/oncotarget.3174.

49. Turrens JF. Mitochondrial formation of reactive oxygen species. The Journal of Physiology. 2003; 552:335-344.

50. Hancock JT, Jones OT. The inhibition by diphenyleneiodonium and its analogues of superoxide generation by macrophages. Biochemical Journal. 1987; 242:103-107. 
51. Sun S-C, Harhaj EW, Xiao G, Good L. Activation of I- $\kappa$ B Kinase by the HTLV Type 1 Tax Protein: Mechanistic Insights into the Adaptor Function of IKK $\gamma$. AIDS research and human retroviruses. 2000; 16:1591-1596.

52. Fleury C, Mignotte B, Vayssiere JL. Mitochondrial reactive oxygen species in cell death signaling. Biochimie. 2002; 84:131-141.

53. Toberer F, Hartschuh W, Hadaschik E. Primary cutaneous CD4+ small- to medium-sized pleomorphic T-cell lymphoma: temporary remission by oral doxycycline. JAMA dermatology. 2013; 149:956-959.

54. Barbie DA, Kennedy BK. Doxycycline: new tricks for an old drug. Oncotarget. 2015; 6:19336-19337. doi: 10.18632/ oncotarget.5111.

55. De Luca A, Fiorillo $M$, Peiris-Pages M, Ozsvari B, Smith DL, Sanchez-Alvarez R, Martinez-Outschoorn UE, Cappello AR, Pezzi V, Lisanti MP, Sotgia F. Mitochondrial biogenesis is required for the anchorageindependent survival and propagation of stem-like cancer cells. Oncotarget. 2015; 6:14777-14795. doi: 10.18632/ oncotarget.4401.

56. Lamb R, Fiorillo M, Chadwick A, Ozsvari B, Reeves KJ, Smith DL, Clarke RB, Howell SJ, Cappello AR, MartinezOutschoorn UE, Peiris-Pages M, Sotgia F, Lisanti MP.
Doxycycline down-regulates DNA-PK and radiosensitizes tumor initiating cells: Implications for more effective radiation therapy. Oncotarget. 2015; 6:14005-14025. doi: 10.18632/oncotarget.4159.

57. Wan L, Dong H, Xu H, Ma J, Zhu Y, Lu Y, Wang J, Zhang T, Li T, Xie J, Xu B, Xie F, Gao Y, Shao J, Tu X, Jia L. Aspirin, lysine, mifepristone and doxycycline combined can effectively and safely prevent and treat cancer metastasis: prevent seeds from gemmating on soil. Oncotarget. 2015; 6:35157-35172. doi: 10.18632/oncotarget.6038.

58. Qin Y, Zhang Q, Lee S, Zhong WL, Liu YR, Liu HJ, Zhao D, Chen S, Xiao T, Meng J, Jing XS, Wang J, Sun $B$, et al. Doxycycline reverses epithelial-to-mesenchymal transition and suppresses the proliferation and metastasis of lung cancer cells. Oncotarget. 2015; 6:40667-40679. doi: 10.18632/oncotarget.5842.

59. Poligone B. (2015). Doxycycline for the Treatment of Cutaneous T-Cell Lymphoma (CTCL). ClinicalTrials.gov. 